\title{
3 Research Square \\ Later onset of hypertension increased the risk of dementia in Mild Cognitive Impairment in community
}

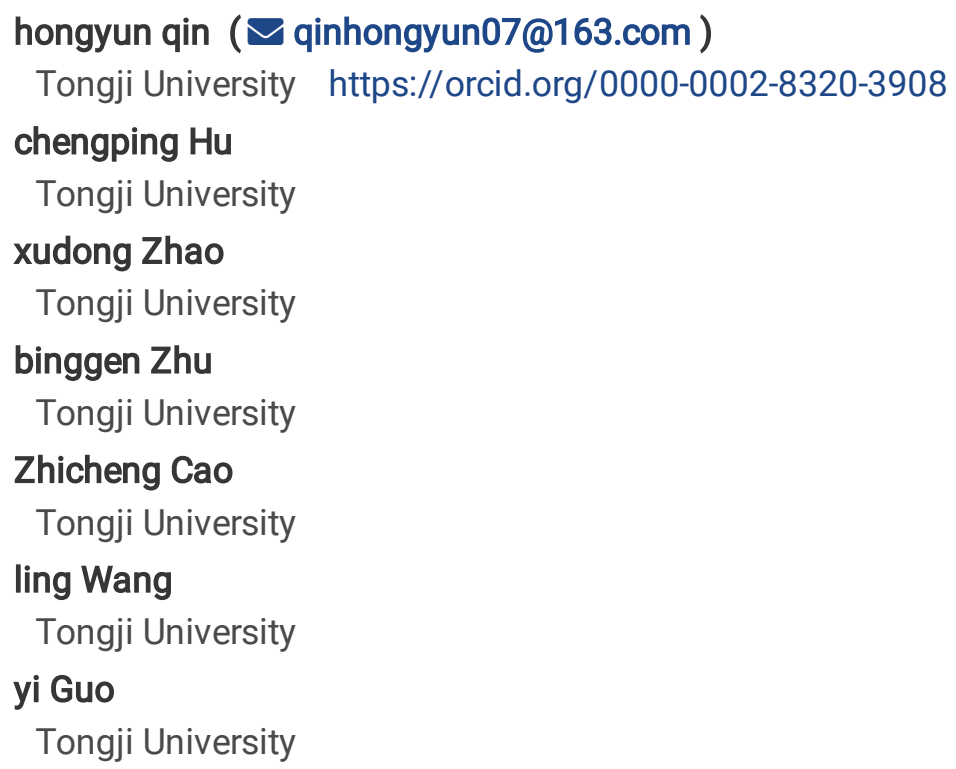

\section{Research article}

Keywords: Mild cognitive impairment, hypertension, dementia, factors, community

Posted Date: August 28th, 2019

DOI: https://doi.org/10.21203/rs.2.12902/v1

License: @ (i) This work is licensed under a Creative Commons Attribution 4.0 International License. Read Full License

Version of Record: A version of this preprint was published at Frontiers in Neurology on November 26th, 2020. See the published version at https://doi.org/10.3389/fneur.2020.557977. 


\section{Abstract}

Objective To investigate the effect of later onset of hypertension on the progression of $\mathrm{MCl}$ in community. Methods Participants are from The Study (NO.PKJ2010-Y26, 2011), a population-based longitudinal cognition survey of people aged $55+$, sampled by probability proportional to size cluster. Hypertension onset age was estimated by self-reported information and medical insurance card records, then classified into two groups: the middle-age group (onset age $<65$ years) and the old-age group (onset age $\geq 65$ years). In order to study the effect of later onset of hypertension on dementia, the incidence of dementia was compared between the two groups. Results A total of 277 hypertensive mild cognitive impairment $(\mathrm{MCl})$ participants without dementia were followed for 6 years. $56 \mathrm{MCl}$ participants $(20.22 \%)$

progressed to dementia (MClp). The proportion of MClp participants in the old-age onset hypertension group ( $\geq 65$ years) was higher than that of middle-age onset one $(27.0 \%$ vs $15.4 \% ; X 2=5.538, P=0.019)$. And in the old-age onset hypertension group, the proportion of MClp without diabetes mellitus was higher than those with diabetes mellitus (24.7\% vs $12.6 \% ; \mathrm{X} 2=5.321, \mathrm{P}=0.021)$, and the proportion of $\mathrm{MClp}$ with increased pulse pressure was higher than those without increased pulse pressure (33.3\% vs $15.4 \% ; \mathrm{X} 2=3.902, \mathrm{P}=0.048)$. However, the multivariate logistic regression analysis showed that older age was the only risk for $\mathrm{MClp}(\mathrm{OR}=0.732, \mathrm{p}=0.029)$. Conclusions These results suggest that, later onset hypertension was harmful to cognition even in cases where the level of blood pressure maintained at $130 / 80 \mathrm{mmHg}$ with antihypertensive management. It is necessary to expand the research sample and improve the experimental methods for further confirmation.

\section{Introduction}

With the advent of population aging, the population of dementia continues to rise, with approximately 47 million people in the whole world in 2015, which is expected to triple by 2050[1]. The two most common types of dementia are Alzheimer's disease $(A D)$ and Vascular dementia $(\mathrm{VaD})$, accounting for about $80 \%$ [1-3]. Mild Cognitive Impairment (MCI) is an intermediate transition stage between normal aging and dementia, which is characterized by mild impairment of cognitive function without decline of daily living or social functioning, and previous studies has shown that all $\mathrm{MCl}$ eventually progressed to dementia (MClp) after 9 years[4]. A multicenter research performed in China from 2008 to 2009 showed that the prevalence rates of $\mathrm{MCl}$ and dementia (> 65 years old) were as high as $20.8 \%$ and $5.14 \%$ respectively [5].

Hypertension is another disease that compromises with the abilities of daily living of the elderly [6, 7]. In the recent twenty years, several studies have found that hypertension is a risk factor not only for VaD and AD, but also for $\mathrm{MCl}[2,7-10]$. In a 2 years follow-up study of $385 \mathrm{MCl}$ cases, Goldstein FC et al. showed that, compared to subjects without hypertension, the cognitive function (such as attention, executive function and naming) of subjects with hypertension declined significantly, especially those with Systolic blood pressure (SBP) $\geq 140 \mathrm{mmHg}$ or Diastolic Blood Pressure (DBP) $\geq 90 \mathrm{mmHg}[11]$. In other words, hypertension is a risk factor for $\mathrm{MCl}$ progression. To date, there is no confirmative effect of nootropic drugs on dementia, whereas hypertension is a very important controllable vascular risk factor[2]. Therefore, it is crucial to quickly identify and manage high-risk patients with hypertension, which will prevent dementia effectively.

It has been found that the incidence of dementia is related to the age onset of hypertension. Numerous studies have shown that middle-aged hypertension is associated with increased dementia twenty or thirty years later, but it is uncertain of later onset hypertension ( $\geq 65$ years) $[9,12]$. For example, some studies have found that hypertension is independently associated with cognitive impairment in later life, the cognitive function declining with increasing SBP, especially SBP $\geq$ $180 \mathrm{mmHg}$ [13-15]. In Yuan's study, the cognition declined with the increased SBP like a hockey [16]. It was also confirmed by cross-sectional survey that, in dementia group, not only the proportion of hypertension (76.5\% vs $59.3 \%$ ), but also the SBP level was higher than that of $\mathrm{MCl}$ group [15]. However, some previous studies performed ten years ago showed that hypertension does not necessarily increase the risk of dementia [2, 17-22]. A 10-year follow-up (averaging 2.8 years) study of 559 over 90 year-olds conducted by Corrada MM et al. had found that the risk of dementia in hypertensive patients aged 80 and 90 was lower than that in non-hypertensive patients [17]. Nevertheless, high SBP level was possibly associated with 
increased risk of dementia for $<75$ year-olds, and it was not the case for $>80$ year-olds [19-22]. Moreover, not the high SBP level, but the increased pulse pressure (PP) was negatively correlated with cognition [23].

Our previous epidemiological investigation found that $\mathrm{MCl}$ with newly onset hypertension ( $\geq 60$ years old) had a higher rate of dementia [on submission]. We then put forth the hypothesis that there may be a particular age (between 60 and 75 years old) when hypertension is harmful to cognitive function. Our objective was to evaluate the association between later onset of hypertension and the risk of all-cause dementia in a population based cohort of individuals.

\section{Materials And Methods}

\subsection{Subjects}

The current research was carried out in Pudong district in Shanghai. We analyzed the elderly with $\mathrm{MCl}$ (age $\geq 60$ years old) who had participated in a survey from June 2011 to June 2012 (No. PKJ2010-Y26) and were successfully contacted in the later survey in 2017. All participants have signed informed consent. Only those sufficiently educated, with enough audiovisual level to complete the necessary examinations were included.

According to the age onset of hypertension, the participants were divided into the old-aged group (onset age $\geq 65$ years) and the middle-aged group (onset age $<65$ years).

\section{$1.2 \mathrm{MCl}$ and dementia diagnostic criteria}

$\mathrm{MCl}$ was diagnosed using the Petersen's diagnostic criteria: (1) the elderly consciously exhibited memory loss, especially those with memory impairment for more than 3 months; (2) the overall cognitive function is normal through the Minimental state examination (MMSE total score: illiterate subjects $>17$, with primary school education $>20$ points, and others > 24 point); (3) clinical dementia rating (CDR) score reached a level of 0.5; (4) Montreal cognitive assessment scale: MoCA score $\leq 26$; (5) with normal function of daily life; (6) the patient did not meet the diagnostic criteria for dementia[24, 25].

The criteria for dementia were as follow. (1) MMSE test: illiterate subjects $\leq 17$, subjects with primary school education $\leq$ 20 points, subjects with education of middle school or above $\leq 24$ points[26]; (2) Those subjects above without definite blindness or speech difficulties.

\subsection{Cognitive and other neuropsychological assessments}

Subjects received the cognitive and other neuropsychological assessments using the following scales where possible: (1) the mini-mental state examination (MMSE) scale[26], (2) Montreal cognitive assessment (MoCA) [25], (3) Hamilton Depression Scale (HAMD-17) [27], (4) Hachinski ischemic index scale (HIS) [28], (5) Activity of Daily Life Scale (ADL) [29], (6) the clinical dementia rating (CDR) scale[30].

\subsection{Diagnosis and treatment of hypertension}

The diagnosis, duration, age of onset, stage and treatment of hypertension were according to elderly self-report and examination of their medical insurance card records.

\subsection{Additional variables:}


Other medical histories reported at the baseline visit and considered as potential confounders included stroke, transient ischemic attack, diabetes, heart disease, and depression. Heart disease included any of the following diseases or surgeries: coronary artery disease, myocardial infarction, atrial fibrillation or other arrhythmias, heart valve disease, congestive heart failure, coronary artery bypass, or pacemaker placement. The highest level of education attained, marital status and occupation were also recorded.

\subsection{Statistical approach:}

Data were analyzed using the Statistical Package for Social Sciences (version 19.0; SPSS, IBM, Chicago, IL, USA). Continuous variables were tested for normality by One-Sample Kolmogorov-Smirnov Test. Continuous variables were expressed as mean $\pm S D$ or median (range) as per distribution type, and categorical data were expressed as frequency and percentages. Statistical analysis was performed using independent samples t-test for normal data and Mann-Whitney $U$ test for non-normal data. Categorical data was analyzed by Chi-square test. The multivariate logistic regression analysis was conducted to identify the determinants of outcome of $\mathrm{MCl}$ following-up. A P value of less than 0.05 was considered statistically significant.

\section{Results}

\subsection{Demographic characteristics of elderly $\mathrm{MCl}$ patients with different onset ages of hypertension in community}

A total of 277 hypertensive participants without dementia were followed for 6 years. The average age of the whole participants was $73.48 \pm 7.47$ years old. The average score of ADL『HAMD-17هHIS, and CDR were 15.15 $\pm 4.68,1.97 \pm 3.21$, $2.67 \pm 1.24$, and $0.58 \pm 0.39$ respectively. The average course of hypertension were $144.70 \pm 117.06$ months, the average of current SBP, DBP and pressure pulse(PP) were $130.53 \pm 11.65,79.87 \pm 8.35$, and $50.76 \pm 13.24(\mathrm{mmHg})$ respectively.

Compared with the middle-age group ( $\mathrm{n}=162)$, the demographic characteristics of hypertensive $\mathrm{MCl}$ patients in the old-age group $(n=115)$ were of older age with less children, marital status (single/ divorced / widowed), less body mass index (BMI) and less co-morbidity with diabetes mellitus(DM), and their diastolic blood pressure (DBP) was slightly lower and CDR scores were higher $(P<0.05)$. (See Table-1). There was no significant difference in gender, occupation, personality characteristics, smoking and alcohol abuse history, family history of dementia between the two groups $(P<0.05)$.

\subsection{Follow-up outcomes of hypertensive $\mathrm{MCl}$ in community}

There were in total 56 individuals (20.22\%) who progressed to dementia (MClp) while 221 (79.78) remained stable (MCls).

More proportions of old-age onset of hypertension and single marital status, higher scores of CDR and ADL in MCIp, and the differences were significantly $(P<0.05)$. However, there is no significant difference in gender, BMI, blood pressure, diabetes mellitus, etc. $(P>0.05)$, as shown in Table -2 .

The proportion of MClp in the old-age onset group without DM and increased PP was higher than the middle- age group, and the difference was significantly $(P<0.05)$, as shown in Table - 3 .

\subsection{Multivariate Logistic Regression Analysis of Cognitive Function deterioration in $\mathrm{MCl}$}


The multivariate logistic regression model was fitted to analyze the determinants of the outcome of $\mathrm{MCl}$ following-up with MClp being 1 and $\mathrm{MCls}$ being 0 . Demographic data and variables such as hypertension, age at onset of hypertension, blood pressure grouping and pulse pressure were taken as independent variables into the model. The variables assignment of logistic regression analysis was listed in table 4 . The results showed that age $(P=0.029)$ was the only independent determinant of outcome of $\mathrm{MCl}$ following-up, while other factors were found to have no significant association with $\mathrm{MClp}$ $(P>0.05)$. The OR of age is 0.732 , which indicates that the younger the age, the more likely the cognitive function of $\mathrm{MCl}$ is to remain stable. See Table 5 for details.

\section{Discussion}

\section{Main Findings}

\subsection{The MClp was higher in the group of onset $\geq 65$ years.}

In this prospective study of 277 mild cognitive impairment participants aged $73.48 \pm 7.47$, later onset of hypertension group ( $\geq 65$ years) was related to a higher dementia risk compared with those of milddle-age one. This increased risk was limited to participants who reported mean SBP was $130 / 80 \mathrm{mmHg}$. In addition, the differences disappeared after stratification according to age, BMI, SBP and DBP levels. To our knowledge, our study is the first to report the level of blood pressure and to include hypertension by age of onset.

Some researchers found that the increased risk of dementia was related to the increase of SBP in the group under 75 years old [17]. The risk of cognitive impairment increased by 1.17 times when SBP was $130-139 \mathrm{mmHg}$, however, it increased to 1.54 times when SBP was $\geq 180 \mathrm{mmHg}$ [16]. The results of 3.8-year follow-up of hypertension $(\mathrm{n}=2800)$ showed that incidences of $\mathrm{MCl}$ and dementia could decrease by $15 \%$ in intensive control of blood pressure (SBP<120 mmHg) compared with the standard control group $(\mathrm{SB}<140 \mathrm{mmHg})(\mathrm{HR}=0.85,95 \% \mathrm{Cl}=0.74-0.97, \mathrm{P}=0.02)$ [31]; moreover, statistically significant reduced risk of $\mathrm{MCl}$ and dementia can be found in the intensive group (SBP $=120 \mathrm{mmHg}$ ) less than 75 years old[32].

The results of this study are not consistent with some results previously published. The reasons may be as follows: Firstly, the average age of the participants in this study was 73 years old with mean SBP $130 / 80 \mathrm{mmHg}, 57 \%$ of them were less than 75 years old, 8 cases (2.89\%) with SBP $<120 \mathrm{mmHg}$ and $8(2.89 \%)$ with SBP $\geq 160 \mathrm{mmHg}$. It could be that the sample size was too small to show statistical differences. Secondly, through medication management with a goal of normal range $(130 / 80 \mathrm{mmHg})$, the proportion of MClp was different between the two groups, suggesting that aggressive lowering of systolic blood pressure may not good for the elderly [2]. Similar findings were found in long-term large sample study ( $\mathrm{n}=$ 1440, 8 years follow-up), the risk of dementia increased by 2.4 times when blood pressure was less than 140/90 mmHg with hypertension from middle to old age.

Furthermore, some studies have found that the relationship between the risk of dementia and the increase of SBP was not clear yet for those older than 85 years [17]. After 10 years of follow-up (average 2.8 years, $n=559$ ), Corrada MM et al. found that the risk of dementia in newly onset hypertension aged $80+$ and $90+$ was lower than that in non-hypertensive patients (HR 0.54 and 0.37, P 0.04 and 0.004, respectively) [17]. The results suggested that the mechanism of hypertension in the elderly was different from that in the middle-aged. Hypertension may be a result of compensatory or response of the body. That is to say, the etiology of hypertension is similar to that of dementia, but the clinical symptoms occur at different times.

In addition, the cognitive impacts of middle-aged hypertension can only be followed up and analyzed after excluding cerebrovascular accidents [21], that is to say, there is bias in the samples. The patients with middle-aged onset hypertension are too serious to detect the impact of hypertension on AD because of cerebrovascular damage such as 
stroke [22]. In addition, other community studies have found that middle-aged hypertension is associated with $\mathrm{MCl}$ and dementia at the age of 70-90, and is more strongly associated with dementia [23]. That is to say, this part of the population did not go through the $\mathrm{MCl}$ stage and directly entered the dementia stage, which is also an aspect of sample bias.

\subsection{The MClp was higher in the group without diabetes mellitus.}

Another finding of the study was that for hypertensive $\mathrm{MCl}$ without diabetes mellitus, the rate of $\mathrm{MClp}$ in the old-age group was 1.96 times higher than that in the middle-age one. One Meta-analysis also found that the predictive ability of cerebrovascular risk factors for dementia/AD in the old-age group (average age 72.3-82.5) was significantly reduced[33]. That is, cerebrovascular diseases such as hypertension, diabetes, hyperlipidemia did not necessarily increase the risk of dementia. A large sample survey of community-based brain magnetic resonance imaging (MRI) follow-up $(n=2367)$ revealed that cerebrovascular risk factors such as white matter degeneration, hypertension, diabetes, smoking were associated with aging and contributed more to dementia, although the age range of this survey was 20-90 years[19]. It should be considered that only 61 cases $(22.02 \%)$ of diabetes mellitus in this study may be due to insufficient sample size, which makes it difficult to reflect statistical differences. In addition, for $\mathrm{MCl}$ aged 73.48 (SD = 7.47), the pathogenesis of diabetes mellitus may be different from that of middle age, so the effect of diabetes mellitus on dementia is also different.

\subsection{The MClp was higher in the group with increased pulse pressure}

The results of this study showed that, the MClp was higher in the increased pulse pressure group, as compared to the normal pulse pressure group. Pulse pressure is a sign of arterial stiffness. It was found that pulse pressure was not associated with hypertension and apolipoprotein E4, but with the deposition of beta-amyloid plaques in the brain[23]. In other words, pulse pressure is closely related to aging.

Jefferson et al. used pulse wave velocity (PWV, $\mathrm{m} / \mathrm{sec}$ ) to measure aortic stiffness and found that the decrease of regional cerebral blood flow was related to the increase of arterial stiffness despite the existence of cerebral blood flow reserve capacity [34]. Follow-up and cross-sectional clinical studies have confirmed that increased pulse pressure increases the risk of dementia (including vascular dementia and Alzheimer's disease), and that the risk of AD is higher in the treatment group, which indicates that medicine may lead to occult hypotension and cerebral hypoperfusion [35].

\subsection{MClp cannot benefit from antihypertensive therapy?}

As for the prevention of dementia by antihypertensive therapy, some studies suggest that the risk of dementia is increased by the potential hypotension in antihypertensive therapy due to the impaired vascular regulation mechanism in the elderly [36-38]. A 16-week follow-up study found that people over 75 years old with $\mathrm{MCl}$ stopped taking antihypertensive drugs and failed to find cognitive function deterioration [38], but the problems in this study were that, it did not point out whether all $\mathrm{MCl}$ was late-onset hypertension and also, the blood pressure increased by $7.36 / 2.63 \mathrm{mmHg}$ after withdrawal, and the follow-up time was too short. A multicenter study found that hypertension patients over 65 years of age had a temporary increase in blood pressure four months after reducing antihypertensive medicine, but recovered to $134 \mathrm{mmHg}$ in nine months, while the control group (without reducing drugs) had an increased risk of emergency hospitalization due to drug interactions[20]. Animal experiments have found that sartan therapy can improve cognition in aged rats [39, 40]. However, clinical studies and meta-analysis show that although antihypertensive therapy can reduce systolic or DBP, it cannot reduce the incidence of dementia $[12,17,23,41]$. 
In conclusion, for the prevention of dementia in elderly with hypertension, a lot of research need to be conducted on the appropriate medicine and proper blood pressure management.

\subsection{Is age a risk factor for MClp?}

In this study, regression analysis failed to decree age onset of hypertension, blood pressure and increased pulse pressure as risk factors for $\mathrm{MCl}$ deterioration, but older age was a risk factor. This is consistent with the results of other studies confirming that old age is the main risk factor for dementia [42].

\subsection{Conclusion}

Antihypertensive therapy with blood pressure level maintained at $130 / 80 \mathrm{mmHg}$ is not necessarily beneficial to cognitive function of late-onset hypertension ( $\geq 65$ years old); late-onset hypertension ( $\geq 65$ years old onset) may have a different pathogenesis from middle-aged hypertension. In future, it is necessary to enlarge research samples and to find appropriate blood pressure for late-onset hypertension.

\section{Research limitations}

First, 277 elderly people with hypertension in $\mathrm{MCl}$ community were followed up prospectively. The sample size was small and the age distribution was uneven. The follow-up time was 6 years. There might be sample bias, and the proportion of MCIp was affected to some extent.

Secondly, the survey of occupational mental activity, post-retirement economic life, lifestyle and other factors in $\mathrm{MCl}$ population with hypertension is not detailed enough, and the influence of insufficient sample size also has some influence on the results of the study.

Thirdly, the diagnosis of dementia in this study sample does not combine the detection of images and CSF biochemical indicators. The history and examination of hypertension are mainly provided by the community elderly and medical record card. There is no 24-hour ambulatory blood pressure monitoring, which may have some bias and have a certain impact on the objectivity of the results.

\section{Research Significance}

Firstly, the results of the current investigation show that $\mathrm{MCl}$ patients with hypertension $\geq 65$ years old) with average age about 73 years old are prone to develop dementia, which suggests that comprehensive consideration should be given to antihypertensive drugs for hypertension ( $\geq 65$ years old). Because of the different mechanisms of hypertension, maintaining blood pressure at 130/80 $\mathrm{mmHg}$ may not have a positive effect on the protection of cognitive function. Secondly, this study shows that pulse pressure has a negtive effect on the protection of cognitive function. In the group of increased pulse pressure, the proportion of senile patients progressing to dementia is higher than that of middle-aged patients. This suggests that, there may be different pathogenesis of hypertension in old age patients, and the effect of increased pulse pressure on cerebrovascular is also increased with age. Therefore, increased pulse pressure may be one of the risk factors of dementia. In the future, it is necessary to expand the research sample and improve the experimental methods for further confirmation.

\section{Declarations}




\section{Funding}

This study was funded by the Health and Family Planning Commission of Pudong New Area, Shanghai (No. PWRd 201705) and the Shanghai Health and Family Planning Commission (No. 201840372).

\section{Conflict of Interest}

No Conflict of Interest.

\section{Ethical examination and approval}

The research project was examined and approved by the ethics committee of the Mental Health Center of Pudong New Area, Shanghai 2017005).

\section{Authors Contribution}

Hongyun Qin and Chengping Hu guided the implementation of research, collated and analyzed the data. Ling Wang was responsible for the quality control and logistics support of the subject. Yi Guo and Zhicheng Cao were responsible for project implementation and data entry. Xudong Zhao and Binggen Zhu were the leader (corresponding authors).

\section{References}

1.Livingston, G., et al., Dementia prevention, intervention, and care. The Lancet, 2017. 390(10113): p. 2673-2734.

2.Tadic, M., C. Cuspidi, and D. Hering, Hypertension and cognitive dysfunction in elderly: blood pressure management for this global burden. BMC Cardiovasc Disord, 2016. 16(1): p. 208.

3.Chan, K. Y., et al., Epidemiology of Alzheimer's disease and other forms of dementia in China, 1990-2010: a systematic review and analysis. The Lancet, 2013. 381(9882): p. 2016-2023.

4.Ward, A., et al., Mild cognitive impairment: disparity of incidence and prevalence estimates. Alzheimers Dement, 2012. $8(1):$ p. 14-21.

5.Jia, J., et al., The prevalence of dementia in urban and rural areas of China. Alzheimers Dement, 2014. 10(1): p. 1-9.

6.Sierra, C., et al., Hypertension and mild cognitive impairment. Curr Hypertens Rep, 2012. 14(6): p. 548-55.

7.Lazo-Porras, M., et al., Cognitive impairment and hypertension in older adults living in extreme poverty: a cross-sectional study in Peru. BMC Geriatr, 2017. 17(1): p. 250.

8.Zuo, M., et al., Physical Predictors of Cognitive Function in Individuals With Hypertension: Evidence from the CHARLS Basline Survey. West J Nurs Res, 2018: p. 193945918770794.

9.Wei, J., et al., Association between hypertension and cognitive function: A cross-sectional study in people over 45 years old in China. J Clin Hypertens (Greenwich), 2018. 20(11): p. 1575-1583.

10.Smith, E. E., et al., Impaired memory is more closely associated with brain beta-amyloid than leukoaraiosis in hypertensive patients with cognitive symptoms. PLoS One, 2018. 13(1): p. e0191345. 
11.Goldstein, F. C., A. I. Levey, and N. K. Steenland, High blood pressure and cognitive decline in mild cognitive impairment. J Am Geriatr Soc, 2013. 61(1): p. 67-73.

12.Harrison, J. K., et al., New horizons: the management of hypertension in people with dementia. Age and Ageing, 2016. 45(6): p. 740-746.

13.Gorelick, P. B., et al., Vascular contributions to cognitive impairment and dementia: a statement for healthcare professionals from the american heart association/american stroke association. Stroke, 2011. 42(9): p. 2672-713.

14.Haring, B., et al., Cardiovascular disease and cognitive decline in postmenopausal women: results from the Women's Health Initiative Memory Study. J Am Heart Assoc, 2013. 2(6): p. e000369.

15.Liang, X., et al., Hypertension and High Blood Pressure Are Associated With Dementia Among Chinese Dwelling Elderly: The Shanghai Aging Study. Front Neurol, 2018. 9: p. 664.

16.Yuan, J. Q., et al., Association Between Late-Life Blood Pressure and the Incidence of Cognitive Impairment: $A$ Community-Based Prospective Cohort Study. J Am Med Dir Assoc, 2018.

17.Corrada, M. M., et al., Age of onset of hypertension and risk of dementia in the oldest-old: The 90+ Study. Alzheimers Dement, 2017. 13(2): p. 103-110.

18.Alzheimer's Association Update. Alzheimer's \& Dementia, 2017. 13(10): p. 1181-1184.

19.Peng, S. L., et al., Age-related changes in cerebrovascular reactivity and their relationship to cognition: A four-year longitudinal study. Neuroimage, 2018. 174: p. 257-262.

20.Gulla, C., et al., Deprescribing antihypertensive treatment in nursing home patients and the effect on blood pressure. J Geriatr Cardiol, 2018. 15(4): p. 275-283.

21.Sharifi, F., et al., Hypertension and Cognitive Impairment: Kahrizak Elderly Study. International Journal of Gerontology, 2011. 5(4): p. 212-216.

22.Alzheimer's Association Update. Alzheimer's \& Dementia, 2018. 14(12): p. 1674-1675.

23.Lima, N. K. C., Hypertension and cognition decline: Is there an ultimate link? J Clin Hypertens (Greenwich), 2018. 20(11): p. $1584-1586$.

24.Luis CA, L. D., Acevedo A, et al., Mild cognitive impairment: directions for future research. Neurology, 2003(61): p. 438444.

25.Chen Jia囚Ye Zirong, Y. M., Fang Ya, the Application and Progression of the Montreal Cognitive Assessment in Mild Cognitive Impairment. Chin J Psvchiatr, 2017. 50(5): p. 386-389.

26.GAO Mingyue, Y. M. K. W.h.Q. P.-y., Factors and validity analysis of MiniðMental State Examination in Chinese elderly people. JOURNAL OF PEKING UNIVERSITY(HEALTH SCIENCES) 2015. 47(3): p. 443-449.

27.Chuanyu, L. F. B. Q. Z. Y. L. H. W., Quality of life and related factors in patients with major depressive disorde. Journal of Capital Medical University, 2017. 38(2): p. 186-191.

28.Wei $囚 \mathrm{CHENHu}$, Z. Q. D.C. W., Study on the relationship between dementia and plasma homocysteine level. Pract Geria, 2017. 29(2): p. 134-136. 
29.Yuan Quan, L. X., Yao Wenbin, the Demandations and factors for long-term care in institutions for disabled elderly. Chinese Journal of Gerontology, 2017(37): p. 6214-6216.

30.Woolf, C., et al., Can the Clinical Dementia Rating Scale Identify Mild Cognitive Impairment and Predict Cognitive and Functional Decline? Dement Geriatr Cogn Disord, 2016. 41(5-6): p. 292-302.

31.Kjeldsen, S. E., et al., Intensive blood pressure lowering prevents mild cognitive impairment and possible dementia and slows development of white matter lesions in brain: the SPRINT Memory and Cognition IN Decreased Hypertension (SPRINT MIND) study. Blood Press, 2018. 27(5): p. 247-248.

32.Zhu, R. X., X. Liu, and Z. Y. He, Association between CLU gene rs 11136000 polymorphism and Alzheimer's disease: an updated meta-analysis. Neurological Sciences, 2018. 39(4): p. 679-689.

33.Hou, X. H., et al., Models for predicting risk of dementia: a systematic review. J Neurol Neurosurg Psychiatry, 2018.

34.Jefferson, A. L., et al., Higher Aortic Stiffness Is Related to Lower Cerebral Blood Flow and Preserved Cerebrovascular Reactivity in Older Adults. Circulation, 2018. 138(18): p. 1951-1962.

35.Oishi, E., et al., Day-to-Day Blood Pressure Variability and Risk of Dementia in a General Japanese Elderly Population: The Hisayama Study. Circulation, 2017. 136(6): p. 516-525.

36.Streit, S., R. K. E. Poortvliet, and J. Gussekloo, Lower blood pressure during antihypertensive treatment is associated with higher all-cause mortality and accelerated cognitive decline in the oldest-old-data from the Leiden 85-plus Study. Age Ageing, 2018. 47(4): p. 545-550.

37.Momtaz, Y. A., et al., Prevalence of hypotension and its association with cognitive function among older adults. Aging Ment Health, 2018. 22(4): p. 447-452.

38.van der Wardt, V., et al., Withdrawal of antihypertensive therapy in people with dementia: feasibility study. Pilot Feasibility Stud, 2018. 4: p. 29.

39.Riley, D. E. and A. J. Espay, Cognitive fluctuations in Parkinson's disease dementia: blood pressure lability as an underlying mechanism. J Clin Mov Disord, 2018. 5: p. 1.

40.Petek, B., et al., Connecting the brain cholesterol and renin-angiotensin systems: potential role of statins and RASmodifying medications in dementia. J Intern Med, 2018. 284(6): p. 620-642.

41.McGuinness, B., et al., Blood pressure lowering in patients without prior cerebrovascular disease for prevention of cognitive impairment and dementia. Cochrane Database Syst Rev, 2009(4): p. CD004034.

42.Liang, X., et al., Mental Work Demands and Late-Life Cognitive Impairment: Results From the Shanghai Aging Study. J Aging Health, 2018: p. 898264318765034.

\section{Tables}

Table 1: Demographic differences of $\mathrm{MCl}$ patients in different age groups of onset of hypertension 


\begin{tabular}{|c|c|c|c|c|c|}
\hline variable & variable level & Middle-aged Group n=162 & Old-age Group n=115 & $\mathrm{X}^{2} / \mathrm{t} / \mathrm{Z}$ value & P value \\
\hline Agelyears! & & $70.45 \pm 6.41$ & $77.75 \pm 6.75$ & $-9.135^{a}$ & $<0.001$ \\
\hline Duration of HT(Months) & & $169.55 \pm 123.08$ & $72.02 \pm 49.63$ & $8.122^{\mathrm{a}}$ & $<0.001$ \\
\hline Current SBPImmHg] & & $131.15 \pm 12.51$ & $129.89 \pm 10.33$ & $0.892^{\mathrm{a}}$ & 0.373 \\
\hline Current DBP (mmHg) & & $80.82 \pm 8.89$ & $78.52 \pm 7.45$ & $2.266^{\mathrm{a}}$ & 0.024 \\
\hline PPImmHgl & & $50.33 \pm 14.82$ & $51.37 \pm 10.64$ & $0.639^{a}$ & 0.524 \\
\hline ADL score & & $14.86 \pm 3.88$ & $15.53 \pm 5.55$ & $-1.125^{\mathrm{a}}$ & 0.262 \\
\hline HAMD-17 score & & $1.86 \pm 2.72$ & $1.74 \pm 2.04$ & $0.412^{\mathrm{a}}$ & 0.680 \\
\hline HIS score & & $2.70 \pm 1.29$ & $2.62 \pm 1.19$ & $0.525^{\mathrm{a}}$ & 0.600 \\
\hline CDR score & & $0.54 \pm 0.35$ & $0.63 \pm 0.44$ & $-2.048^{\mathrm{a}}$ & 0.041 \\
\hline \multirow[t]{2}{*}{ BMI Grouping } & $\geq 28$ & 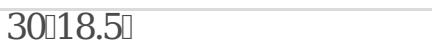 & $10 \square 8.7 \square$ & $7.455^{b}$ & 0.024 \\
\hline & $\begin{array}{l}24-27.99 \\
<24\end{array}$ & 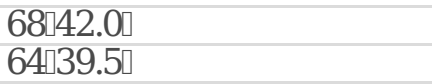 & $\begin{array}{l}\text { 44П38.3■ } \\
61 \square 53.0 \square\end{array}$ & & \\
\hline Number of Child(ren) & & $2 \square 1-3 \square$ & 1๑1-2】 & $-5.751^{c}$ & $<0.001$ \\
\hline Marital Status & Yes & $20 \llbracket 12.3 \square$ & $30 \rrbracket 26.1 \square$ & $8.585^{b}$ & 0.003 \\
\hline (singleness) & No & 142【87.7ฤ & $85 \square 73.9 \square$ & & \\
\hline $\mathrm{DM}$ & Yes & $44 \llbracket 26.5 \square$ & 17\15.7ฤ & $4.646^{\mathrm{b}}$ & 0.031 \\
\hline Gender & $\begin{array}{l}\text { No } \\
\text { Male }\end{array}$ & $\begin{array}{l}119 \square 73.5[ \\
37 \square 22.8 \square\end{array}$ & $\begin{array}{l}97 \square 84.3 \square \\
34 \square 29.6 \square\end{array}$ & $1.596^{b}$ & 0.206 \\
\hline Previous Occupation & $\begin{array}{l}\text { Female } \\
\text { Mental Labour }\end{array}$ & $\begin{array}{l}125 \square 77.2] \\
17 \square 10.7 \square\end{array}$ & $\begin{array}{l}81 \llbracket 70.4 \rrbracket \\
12 \square 10.7 \rrbracket\end{array}$ & $0.000^{\mathrm{b}}$ & 0.995 \\
\hline Educational & $\begin{array}{l}\text { Physical Labour } \\
<12 \text { years }\end{array}$ & $\begin{array}{l}142 \square 89.3 \square \\
152 \square 93.8 \square\end{array}$ & $\begin{array}{l}100 \square 89.3 \square \\
109 \square 94.8 \square\end{array}$ & $0.113^{b}$ & 0.737 \\
\hline Qualification & $\geq 12$ years & $10 \square 6.2 \rrbracket$ & $615.2 \square$ & & \\
\hline Hyperlipidemia & $\begin{array}{l}\text { Yes } \\
\text { No }\end{array}$ & $\begin{array}{l}\text { 17〕10.5[ } \\
145 \square 89.5 \square\end{array}$ & $\begin{array}{l}\text { 11ロ9.6ロ } \\
104 \square 90.4 \square\end{array}$ & $0.604^{\mathrm{b}}$ & 0.801 \\
\hline Family history of dementia & Yes & 7\4.3】 & $4 \rrbracket 3.4 \square$ & $0.135^{\mathrm{b}}$ & 0.731 \\
\hline History of memory loss & $\begin{array}{l}\text { No } \\
\text { Yes }\end{array}$ & 155[95.7ฤ & $\begin{array}{l}111[96.6 \square \\
99 \square 86.10\end{array}$ & $1.076^{\mathrm{b}}$ & 0.300 \\
\hline Smoking & $\begin{array}{l}\text { No } \\
\text { Yes }\end{array}$ & $\begin{array}{l}30 \square 18.6 \square \\
12 \square 7.4 \square\end{array}$ & $\begin{array}{l}16 \rrbracket 13.9 \square \\
6 \llbracket 5.2 \square\end{array}$ & $0.531^{\mathrm{b}}$ & 0.466 \\
\hline Alcohol Consumption & $\begin{array}{l}\text { No } \\
\text { Yes }\end{array}$ & $\begin{array}{l}150 \square 92.6 \square \\
10 \square 6.2 \square\end{array}$ & $\begin{array}{l}109 \square 94.8 \square \\
6 \square 5.2 \square\end{array}$ & $0.113^{b}$ & 0.737 \\
\hline Increased PP & $\begin{array}{l}\text { No } \\
\text { Yes }\end{array}$ & $\begin{array}{l}152 \rrbracket 93.80 \\
52 \rrbracket 59.1 \square\end{array}$ & $\begin{array}{l}109 \square 94.8 \square \\
36 \llbracket 40.9 \square\end{array}$ & $0.020^{\mathrm{b}}$ & 0.889 \\
\hline \multirow[t]{2}{*}{ SBP } & $\begin{array}{l}\text { No } \\
<120\end{array}$ & $\begin{array}{l}110 \square 58.2 \square] \\
5\end{array}$ & $\begin{array}{l}79 \square 41.8[ \\
3\end{array}$ & $3.664^{b}$ & 0.300 \\
\hline & $\begin{array}{l}120-139 \\
140-159 \\
\geq 160\end{array}$ & $\begin{array}{l}105 \\
45 \\
7\end{array}$ & $\begin{array}{l}83 \\
28 \\
1\end{array}$ & & \\
\hline \multirow[t]{2}{*}{ DBP } & $<70$ & 3 & 6 & $3.764^{b}$ & 0.288 \\
\hline & $\begin{array}{l}70-89 \\
90-109 \\
\geq 110 \\
\end{array}$ & $\begin{array}{l}132 \\
26 \\
1\end{array}$ & $\begin{array}{l}95 \\
14 \\
0 \\
\end{array}$ & & \\
\hline
\end{tabular}

Note【HT: hypertension. SBP: Systolic blood pressure. DBP: Diastolic blood pressure. PP: pulse pressure $=$ Systolic minus Diastolic pressure. ADL: Activity of Daily Life. HAMD: Hamilton Depression Scale. HIS: Hachinski ischemic index scale. CDR: Clinical Dementia Rating. BMI: Body Mass Index. DM: Diabetes

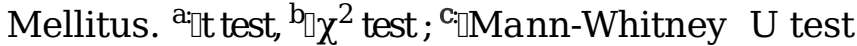

Table 2هFollow-up outcomes of hypertensive MCI 


\begin{tabular}{|c|c|c|c|c|c|}
\hline variable & Variable leve & MCIp & MCIs & $\chi^{2} / \mathrm{t}$ & $P$ \\
\hline \multirow[t]{2}{*}{ Age } & $<65$ & $25 \square 15.4 \% \square$ & $137 \square 84.6 \% \square$ & $5.538^{a}$ & 0.019 \\
\hline & $\geq 65$ & 31凸27.0\%ロ & 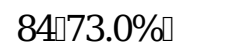 & & \\
\hline \multicolumn{2}{|l|}{ HAMD-17 score } & $2.34 \pm 3.42$ & $1.67 \pm 2.14$ & $1.406^{\mathrm{b}}$ & 0.165 \\
\hline CDR score & \multicolumn{2}{|c|}{$0.75 \pm 0.51$} & $0.54 \pm 0.35$ & $-4.666^{b}$ & $<0.001$ \\
\hline \multicolumn{2}{|l|}{ ADL score } & $18.04 \pm 9.05$ & $14.42 \pm 2.07$ & $2.973^{b}$ & 0.004 \\
\hline \multicolumn{2}{|l|}{ HIS score } & $2.96 \pm 1.76$ & $2.59 \pm 1.07$ & $1.512^{\mathrm{b}}$ & 0.135 \\
\hline \multirow[t]{2}{*}{ Gender } & male & 14₫19.7凹 & 57ロ80.3ロ & $0.015^{\mathrm{a}}$ & 0.904 \\
\hline & female & $42 \square 20.4 \square$ & $164 \square 79.6 \square$ & & \\
\hline \multirow[t]{2}{*}{ Singleness } & Yes & $16 \llbracket 32.0 \square$ & $34 \llbracket 68.0 \square$ & $5.252^{\mathrm{a}}$ & 0.022 \\
\hline & No & $40 \square 17.6 \square$ & 187\82.4】 & & \\
\hline \multirow[t]{2}{*}{$\mathrm{DM}$} & Yes & 17ロ58.8】 & $44 \llbracket 41.2 \square$ & $2.840^{\mathrm{a}}$ & 0.092 \\
\hline & No & $39 \square 18.1$ & $177 \square 81.9]$ & & \\
\hline \multirow[t]{3}{*}{ BMI } & $\geq 28$ & $6 \rrbracket 13.0 \square$ & $42 \square 87.0 \square$ & $1.006^{\mathrm{a}}$ & 0.605 \\
\hline & $24-27.99$ & 28ロ18.7\ & 122凸81.3! & & \\
\hline & $<24$ & $42 \square 17.5 \square$ & 191口79.6] & & \\
\hline \multicolumn{2}{|l|}{ SBP\mmHgl } & $131.48 \pm 12.04$ & $130.41 \pm 11.57$ & $0.613^{b}$ & 0.540 \\
\hline \multicolumn{2}{|l|}{ DBPImmHgl } & $80.09 \pm 7.10$ & $79.81 \pm 8.69$ & $0.222^{\mathrm{b}}$ & 0.824 \\
\hline \multicolumn{2}{|l|}{ PPlmmHgl } & $51.39 \pm 12.00$ & $50.60 \pm 13.55$ & $0.399^{b}$ & 0.690 \\
\hline \multirow[t]{2}{*}{ Increased PP } & Yes & $20 \llbracket 19.0 \square$ & 68凸81.0ロ & $0.504^{\mathrm{a}}$ & 0.478 \\
\hline & No & 36ロ22.7\ & 153ロ77.3■ & & \\
\hline \multirow[t]{4}{*}{ SBP $\llbracket m m H g]$} & $<120$ & 0 & 8ロ100】 & $2.486^{\mathrm{a}}$ & 0.478 \\
\hline & 120-139 & 39ロ20.7 & 149079.3 & & \\
\hline & $140-159$ & $16 \square 21.9 \square$ & 57\78.1口 & & \\
\hline & $\geq 160$ & 1₫12.5凸 & 7ロ87.5凸 & & \\
\hline \multirow[t]{4}{*}{ DBP (mmHg) } & $<70$ & $2 \llbracket 22.2 \square$ & 7ロ77.8\ & $0.941^{\mathrm{a}}$ & 0.816 \\
\hline & $70-89$ & 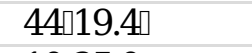 & 166ロ80.6] & & \\
\hline & $90-109$ & $10 \square 25.0 \square$ & 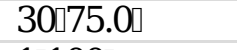 & & \\
\hline & $\geq 110$ & 0 & $1 \square 100 \square$ & & \\
\hline
\end{tabular}

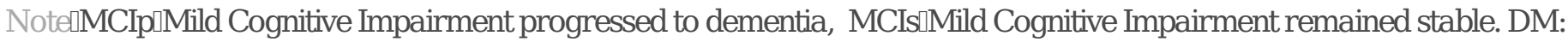
Diabetes Mellitus. BMI: Body Mass Index. SBP: Systolic blood pressure. DBP: Diastolic blood pressure, PP: pulse pressure= Systolic minus Diastolic pressure, Increased PP : PP >60mmHg. ${ }^{\mathrm{a}} \chi^{2}$ test, ${ }^{\mathrm{b}} \mathrm{tt}$ test

Table 3区Follow-up outcomes of hypertensive $\mathrm{MCl}$ stratified by age of onset 


\begin{tabular}{|c|c|c|c|c|c|c|c|c|c|}
\hline \multirow[t]{2}{*}{ variable } & \multirow{2}{*}{$\begin{array}{c}\text { Variable } \\
\text { level }\end{array}$} & \multicolumn{2}{|c|}{$<65$} & \multirow{2}{*}{$\chi^{2} / \mathrm{t}$} & \multirow[t]{2}{*}{$P$} & \multicolumn{2}{|c|}{$\geq 65$} & \multirow{2}{*}{$\chi^{2} / \mathrm{t}$} & \multirow[t]{2}{*}{$P$} \\
\hline & & MCIp & MCIs & & & MCIp & MCIs & & \\
\hline $\begin{array}{l}\text { HAMD-17 } \\
\text { score }\end{array}$ & & $2.80 \pm 4.59$ & $1.69 \pm 2.21$ & $1.188^{a}$ & 0.245 & $2.00 \pm 2.05$ & $1.64 \pm 2.03$ & $\begin{array}{l}0.863 \\
\mathrm{a}\end{array}$ & 0.390 \\
\hline CDR score & & $0.66 \pm 0.40$ & $0.52 \pm 0.34$ & $\begin{array}{l}-2.608 \\
\mathrm{a}\end{array}$ & 0.009 & $0.81 \pm 0.58$ & $0.56 \pm 0.36$ & $\begin{array}{l}-3.559 \\
a\end{array}$ & $<0.001$ \\
\hline ADL score & & $17.36 \pm 8.50$ & $14.40 \pm 1.93$ & $1.733^{\mathrm{a}}$ & 0.096 & $18.44 \pm 9.46$ & $14.44 \pm 2.27$ & $\begin{array}{l}2.368 \\
\mathrm{a}\end{array}$ & 0.024 \\
\hline HIS score & & $3.00 \pm 1.91$ & $2.65 \pm 1.15$ & $\begin{array}{l}0.886 \\
\mathrm{a}\end{array}$ & 0.383 & $2.88 \pm 1.66$ & $2.53 \pm 0.96$ & $\begin{array}{l}1.110 \\
\mathrm{a}\end{array}$ & 0.274 \\
\hline \multirow[t]{2}{*}{ Gender } & male & $5 \square 13.5 \square$ & $32 \llbracket 86.5 \square$ & & & $9026.5 \square$ & 25[73.5ロ & $\begin{array}{l}1.879 \\
b\end{array}$ & 0.170 \\
\hline & female & $20 \square 16.0 \square$ & $105 \square 84.0 \square$ & & & $22 \rrbracket 27.2 \square$ & $59[72.8 \square$ & $\begin{array}{l}3.772 \\
b\end{array}$ & 0.052 \\
\hline \multirow[t]{2}{*}{ Singleness } & Yes & $4 \llbracket 20.0 \square$ & $16 \square 80.0 \square$ & & & $12 \square 40.0 \square$ & $18 \square 60.0 \square$ & $\begin{array}{l}2.206 \\
b\end{array}$ & 0.137 \\
\hline & No & 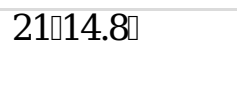 & $121 \square 85.2 \square$ & & & $19 \square 22.4 \square$ & 66ロ77.6] & $\begin{array}{l}2.096 \\
b\end{array}$ & 0.148 \\
\hline \multirow[t]{2}{*}{$\mathrm{DM}$} & Yes & 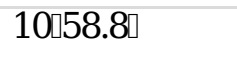 & $7 \rrbracket 41.2 \square$ & & & $33 \square 75.0 \square$ & $11 \llbracket 25.0 \square$ & $\begin{array}{l}1.543 \\
\mathrm{~b}\end{array}$ & 0.214 \\
\hline & No & 15(12.6) & $104 \square 87.4 \square$ & & & 24】24.7\ & 73ロ75.3■ & $\begin{array}{l}5.321 \\
b\end{array}$ & 0.021 \\
\hline \multirow[t]{3}{*}{ BMI } & $\geq 28$ & $3 \square 10.0 \square$ & $27 \rrbracket 90.0 \square$ & & & 3ロ30.0ロ & 7\70.0】 & $2.353^{\mathrm{b}}$ & 0.125 \\
\hline & $\begin{array}{l}24- \\
27.99\end{array}$ & 11ロ16.2凹 & 57\83.8[ & & & 14п31.8[ & $30 \square 68.2 \square$ & $3.770^{b}$ & 0.052 \\
\hline & $<24$ & 11घ17.2】 & 53ロ82.8ロ & & & $14 \llbracket 23.0 \square$ & 47ロ77.0】 & $0.648^{b}$ & 0.421 \\
\hline $\mathrm{SBP}(\mathrm{mmHg})$ & & $131.92 \pm 13.20$ & $131.01 \pm 12.43$ & $\begin{array}{l}0.332 \\
\mathrm{a}\end{array}$ & 0.740 & $130.78 \pm 11.22$ & $129.55 \pm 10.02$ & $\begin{array}{l}0.543 \\
\mathrm{a}\end{array}$ & 0.590 \\
\hline $\mathrm{DBP}(\mathrm{mmHg})$ & & $80.40 \pm 5.94$ & $80.90 \pm 9.34$ & $\begin{array}{l}-0.257 \\
a\end{array}$ & 0.798 & $79.84 \pm 7.88$ & $78.12 \pm 7.21$ & $\begin{array}{l}1.125 \\
\mathrm{a}\end{array}$ & 0.263 \\
\hline $\mathrm{PP}(\mathrm{mmHg})$ & & $51.52 \pm 11.02$ & $50.12 \pm 15.44$ & $\begin{array}{l}0.434 \\
\mathrm{a}\end{array}$ & 0.665 & $51.29 \pm 12.91$ & $51.39 \pm 9.76$ & $\begin{array}{l}-0.040 \\
a\end{array}$ & 0.968 \\
\hline \multirow[t]{2}{*}{$\begin{array}{l}\text { Increased } \\
\text { PP }\end{array}$} & Yes & 8ロ15.4】 & $44 \llbracket 84.6 \square$ & & & 12ஐ33.3] & 24匹66.7】 & $\begin{array}{l}3.902 \\
b\end{array}$ & 0.048 \\
\hline & No & 17凸15.5ロ & 93凸84.5凸 & & & $19 \square 24.1 \square$ & $60 \square 75.9 \square$ & $\begin{array}{l}2.203 \\
b\end{array}$ & 0.138 \\
\hline
\end{tabular}

MCIp\Mild Cognitive Impairment progressed to dementia, MCIs\Mild Cognitive Impairment remained stable. DM: Diabetes Mellitus. BMI: Body Mass Index. SBP: Systolic blood pressure. DBP: Diastolic blood pressure, PP: pulse pressure= Systolic minus Diastolic pressure, Increased PP : PP >60mmHg. ${ }^{a}$ it test, ${ }^{b} \chi^{2}$ test

Table 4囚The variables assignment of Multivariate logistic regression analysis 


\begin{tabular}{lll}
\hline variable & Factors & \multicolumn{1}{c}{ Assignment } \\
\hline X1 & Gender & Male=1, Female=2 \\
X2 & Educational level & $<12$ years $=1, \geq 12$ years $=2$ \\
X3 & Singleness & Yes $=1$, No $=2$ \\
X4 & Occupation & Mental labor $=1$, Physical labor $=2$ \\
X5 & Diabetes Mellitus & Yes $=1$, No $=2$ \\
X6 & Hyperlipidemia & Yes $=1$, No $=2$ \\
X7 & Smoking & Yes $=1$, No $=2$ \\
X8 & Alcohol Consumption & Yes $=1$, No $=2$ \\
X9 & History of Dementia & Yes $=1$, No $=2$ \\
X10 & Hypertension alone & Yes $=1$, No $=2$ \\
X11 & Increased pulse pressure & Yes $=1$, No $=2$ \\
X12 & Hypertension age of onset & $<65$ years $=1, \geq 65$ years=2 \\
\hline
\end{tabular}

Table 5囚Results of multivariate logistic regression model

\begin{tabular}{|c|c|c|c|}
\hline & $\begin{array}{ll}\text { S.E. } & P\end{array}$ & $\begin{array}{r}95 \% \text { C.I } \\
\text { Lower limit }\end{array}$ & $\begin{array}{l}\text { of OR } \\
\text { Upper limit }\end{array}$ \\
\hline Gender & -0.3950 .5080 .4370 .673 & 0.249 & 1.823 \\
\hline Education level & 0.0590 .9640 .9511 .061 & 0.160 & 7.020 \\
\hline Age & -0.3240 .1660 .0290 .723 & 0.502 & 0.964 \\
\hline Singleness & -0.4400 .4870 .3670 .644 & 0.248 & 1.673 \\
\hline Occupation & -0.6830 .5900 .2470 .505 & 0.159 & 1.604 \\
\hline Number of children & 0.4170 .2400 .0821 .517 & 0.949 & 2.428 \\
\hline Diabetes Mellitus & 0.2500 .5490 .6491 .284 & 0.438 & 3.766 \\
\hline Hyperlipidemia & -1.5081 .0530 .1520 .221 & 0.028 & 1.744 \\
\hline Smoking & 0.2431 .0010 .8081 .275 & 0.179 & 9.078 \\
\hline Alcohol Consumption & -0.8031 .1350 .4790 .448 & 0.048 & 4.146 \\
\hline History of Dementia & 0.9460 .9500 .3202 .575 & 0.400 & 16.573 \\
\hline BMI & -0.2540 .3010 .4000 .776 & 0.430 & 1.401 \\
\hline Hypertension alone & 0.4490 .4710 .3411 .567 & 0.622 & 3.949 \\
\hline Systolic Pressure & -0.0590 .4890 .9040 .943 & 0.361 & 2.457 \\
\hline Diastolic Pressure & 0.1940 .4740 .6821 .214 & 0.480 & 3.072 \\
\hline Increased pulse pressure & 0.0680 .4310 .8741 .070 & 0.460 & 2.490 \\
\hline Hypertension age of onse & t0.218 0.3750.5611.244 & 0.596 & 2.596 \\
\hline
\end{tabular}

